\title{
Engineering Studies in Support of the Development of High-Speed Track Geometry Specifications
}

\author{
Magdy El-Sibaie \\ David Jamieson \\ Federal Railroad Administration \\ Washington, DC 20590
}

\author{
David C. Tyrell \\ J. Christopher Dorsey \\ Volpe National Transportation Systems Center \\ US Department of Transportation \\ Cambridge, MA 02142
}

\author{
Brian Mee \\ Brian Whitten \\ Kevin Kesler \\ ENSCO, Inc. \\ Springfield, VA 22151
}

\section{ABSTRACT}

The Federal Railroad Administration has been directing engineering studies to support the development of high speed track geometry standards. These standards are intended to cover train operating speeds from $110 \mathrm{mph}$ to $200 \mathrm{mph}$. The studies conducted include evaluation of the use of measuring track geometry with offsets from several chord lengths, computer simulations of vehicle response to track surface and alignment variations, application of the proposed specifications to previously measured track geometry, and comparison of proposed specifications to foreign practice.

The proposed standards use multiple chords to control surface and alignment geometry. Single isolated geometry variations are allowed greater amplitudes than three or more repeated geometry variations. The results of the engineering studies indicate that use of multiple chords is effective in controlling a wide range of geometry variation wavelengths, from less than 30 feet to greater than 250 feet. The computer simulation studies show that at high speed, wheel/rail interaction dominates vehicle response to short wavelength (less than 100 feet) alignment variations, while carbody motions dominate vehicle response to long wavelength variations. Derailment and carbody accelerations are the principal concerns in vehicle response to track geometry variations. Application of the proposed specifications to previous measurements of high speed track on the Northeast Corridor indicates a relatively modest number of exception locations ( 1 location every 3 miles). Comparison of the proposed specification with foreign practice indicates that the proposed specification provides a generally similar level of control of track geometry.

\section{INTRODUCTION}

The Federal Railroad Administration formally established the Railroad Safety Advisory Committee (RSAC) on March 25, 1996 to provide FRA with advice and recommendations on regulatory issues. RSAC is comprised of approximately 48 representatives of organizations interested in railroad safety, including railroads, labor, manufacturers, state government groups and public interest associations.

The RSAC met in April, 1996 and agreed to consider four tasks, one of which was the revision of the track safety standards. At the meeting, the RSAC established several working groups, including the Track Working Group. The Working Group assigned a task group to develop recommendations for high speed track safety standards. The High Speed Task Group, comprised of representatives from rail labor, Amtrak, private associations, and government, met for the first time in June of 1996 to begin its discussions. At its first meeting, the Task Group voted to request that FRA's Office of Research and Development organize an effort which would provide the Task Group with recommendations on vehicle/track interaction limits and track geometry.

The High Speed Task Group developed recommendations for modifications to existing Class 6 track standards and new track standards for Classes 7, 8 and 9. The cornerstone of the recommended standards are the vehicle/track interaction safety limits and the proposed track geometry specifications. These proposed specifications limit track geometry based on the potential for derailment and on the potential for passenger injury owing to excessive carbody accelerations. This paper describes the proposed specifications and summarizes the results of some of the studies conducted to develop the proposed specifications. 


\section{DESCRIPTION OF PROPOSED HIGH SPEED STANDARDS}

Track geometry is described by track profile, crosslevel, alignment, and gage. Track profile is the variation in elevation of each rail, while track crosslevel is the difference between the left and right rail elevations. Track alignment is the variation in curvature of the track and gage is the distance between the two rails measured 5/8 inches down from the top of each rail.

As a rail vehicle travels, it responds to track geometry variations and irregularities. Track crosslevel variations and irregularities can cause carbody roll, sway, and twist. Track profile irregularities can cause carbody pitch and bounce. Excessive carbody motions can result in wheel unloading or excessive carbody accelerations. Track alignment and gage variations can lead to large lateral wheel and axle forces, resulting in derailment or damage to the track structure. When an encounter with a track geometry variation or series of variations results in an unsafe response --derailment or excessive carbody acceleration-- of a rail vehicle, the safe limits of geometry variations have been exceeded.

The proposed high speed track geometry specifications limit variations in track surface, twist, alignment and gage. Track crosslevel is limited by the maximum superelevation and track twist specifications, which is defined as the change in crosslevel in 62 feet or less. Table 1 lists the high speed track geometry specifications recommended by the High Speed Task Group.

Table 1. High Speed Track Classes, Maximum Operating Speeds, and Track Geometry Limits.

\begin{tabular}{|c|c|c|c|c|c|}
\hline & Class & 6 & 7 & 8 & 9 \\
\hline & $\begin{array}{l}\text { Maximum } \\
\text { Speed }\end{array}$ & $\begin{array}{l}110 \\
\mathrm{mph}\end{array}$ & $\begin{array}{l}125 \\
\mathrm{mph}\end{array}$ & $\begin{array}{l}160 \\
\mathrm{mph}\end{array}$ & $\begin{array}{l}200 \\
\mathrm{mph}\end{array}$ \\
\hline Parameter & Chord & \multicolumn{4}{|c|}{ Maximum Mid-Chord Offset (in.) } \\
\hline \multirow{3}{*}{$\begin{array}{l}\text { Alignment } \\
\text { (single) }\end{array}$} & $31^{\prime}$ & 0.50 & 0.50 & 0.50 & 0.50 \\
\hline & $62^{\prime}$ & 0.75 & 0.50 & 0.50 & 0.50 \\
\hline & 124' & 1.50 & 1.25 & 0.75 & 0.75 \\
\hline \multirow{3}{*}{$\begin{array}{l}\text { Alignment } \\
\text { (repeated) }\end{array}$} & $31^{\prime}$ & 0.375 & 0.375 & 0.375 & 0.375 \\
\hline & 62 ' & 0.50 & 0.375 & 0.375 & 0.375 \\
\hline & $124^{\prime}$ & 1.00 & 0.875 & 0.50 & 0.5 \\
\hline \multirow{3}{*}{$\begin{array}{l}\text { Surface } \\
\text { (single) }\end{array}$} & 31' & 1.25 & 1.25 & 0.75 & 0.50 \\
\hline & $62^{\prime}$ & 1.25 & 1.25 & 1.25 & 1.00 \\
\hline & 124 & 1.75 & 1.50 & 1.25 & 1.25 \\
\hline \multirow{3}{*}{$\begin{array}{l}\text { Surface } \\
\text { (repeated) }\end{array}$} & $31^{\prime}$ & 0.875 & 0.875 & 0.50 & 0.375 \\
\hline & $62^{\prime}$ & 0.875 & 0.875 & 0.875 & 0.75 \\
\hline & $124^{\prime}$ & 1.25 & 1.00 & 0.875 & 0.875 \\
\hline Twist & "Within 62' & 1.50 & 1.50 & 1.50 & 1.50 \\
\hline \multirow[t]{3}{*}{ Gage } & "Minimum & ב56.00 & ב56.00 & 565.00 & 56.25 \\
\hline & Maximum & 57.25 & 57.25 & 57.25 & 57.25 \\
\hline & $\begin{array}{l}\text { Change per } \\
31 \text {, }\end{array}$ & 0.50 & 0.50 & 0.50 & 0.50 \\
\hline $\begin{array}{l}\text { Super- } \\
\text { elevation }\end{array}$ & Maximum & 7 & 7 & 7 & 7 \\
\hline
\end{tabular}

The considerations in developing the recommended geometry specifications for high speed track, in addition to derailment potential and excessive carbody accelerations, included existing
US practice on conventional speed track, and the RSAC decision not to recommend the addition of metric units to the track safety standards. Existing practice extensively employs the deviation of the track at the mid-ordinate of a 62 foot long chord, for measurement of both rail surface and alignment. Midchord offset measurements can be easily made by hand, as well as with automatic track geometry measurement equipment.

For limits on track alignment and surface variations, chords of 31 and 124 foot lengths, in addition to the traditional 62 foot length, were selected. If mid-chord offsets are to be used as the principal measures of track geometry, then multiple chord lengths are necessary to identify track geometry variations over the range of wavelengths which influence vehicle dynamics at high speed. In order to extend the wavelength range beyond that of the traditional 62 foot chord, chords of half and twice the traditional length were added.

The 31-foot chord was selected to control short wavelength defects that can result in high wheel forces over a short portion of track. These forces may not produce excessive carbody motion yet their action on the wheels and truck may cause derailment. Most foreign high speed railroads use a 10-meter chord which is approximately equal in length to the 31 -foot chord.

The 62-foot chord was selected due to its proximity to the truck center spacing of most high speed passenger vehicles. In phase carbody modes such as sway and bounce are affected by track anomalies with a wavelength that is near the truck center spacing. Control of track geometry limits based on the 62 -foot chord help limit the magnitude of such carbody motion. This chord also is used for track classes 1-5 and is familiar to track inspection and maintenance personnel.

The 124-foot chord, which is approximately equal to 40 meters, was selected to provide a means to locate and measure longer wavelength track anomalies. These long-wavelength anomalies provide dynamic input to the high speed passenger vehicles and can excite carbody modes at high speeds. Excessive carbody motion can result in unacceptable carbody accelerations. Addition of this chord length allows measurement of anomalies with wavelengths up to 300 feet. To control longer wavelengths, most foreign high speed railroads use a 30 or 40 -meter chord. A 40-meter chord was adopted by the Japanese National Railway (JNR) after recent speed increases on their Tokaido line. JNR research and testing indicates a strong correlation between carbody motion and track geometry limits based on 40-meter mid-chord offsets (Takai, H., Yazawa, E., 1994.)

Repeated track geometry variations can cause the dynamic buildup of carbody motions and of wheel/rail forces. In general, larger amplitude track geometry variations can be safely traversed if there is only a single variation, rather than repeated variations. Accordingly, the proposed standards include tighter tolerances for repeated track geometry variations than for single track geometry variations. Repeated track geometry variations are defined as non-overlapping, and occurring three or more times within a distance equal to five times the chord length. 
A uniform curve will have a constant mid-chord offset over its entire length; the mid-chord offset, measured laterally, is the typical field measure of track curvature. Track geometry variations in curves are measured as variations in the mid-chord offset from the mid-chord offset associated with the uniform curve (or desired curvature). Track inspectors typically determine uniformity on tangents as a straight line and uniformity in curves as an average of a sufficient number of mid-chord offset measurements. In spirals, inspectors determine uniformity by establishing a uniform slope; however, the determination where the spiral begins and ends is often subjective. The same difficulty is sometimes present in the transition areas of compound curves. Consequently, a definition of uniformity that can be applied at any point on the track, including transition points, was developed. The proposed definition of uniformity is the average of nine measurements taken at consecutive locations on the track separated by a $1 / 4$ chord length.

Definitions of average elevation and average curvature for use in computing the speed limits in curves were recommended. The proposed average elevation and curvatures are computed from measurements made at 10 locations on the track separated by $151 / 2$ feet. For curves less than 155 feet in length, the averages are computed from measurements made at 10 locations on the track which are evenly separated. The formula for the speed limit in curves is based on ride comfort considerations (Manual for Railway Engineering, 1996.) Computing elevation and curvature as averages over a length of track recognizes the "steady state" purpose of the formula.

\section{DESCRIPTION OF VEHICLE/TRACK INTERACTION SAFETY LIMITS}

The potential for derailment and excessive carbody accelerations -sufficient to cause a standing passenger to fall-limit safe track geometry. Table 2. lists the derailment and acceleration criteria and their limits recommended by the High Speed Task Group. The first four limits are on the vertical and lateral forces occurring at the wheel/rail interface and are required in order to minimize the risk of vehicle derailment. The last three limits are on carbody or truck accelerations to prevent hazardous or unsafe vehicle motions.

A minimum vertical load ratio of 0.1 ensures that no wheel is permitted to unload to a level at which the risk for various derailment modes greatly increases. A limit on any single wheel's L/V (or lateral to vertical load) ratio as defined by the formula in this table (Nadal, 1896) ensures that the risk of wheel climb derailment is minimized. A maximum limit on the net $\mathrm{L} / \mathrm{V}$ ratio on any axle of 0.5 ensures that the risk of derailment due to track panel shift is minimized. And finally, a maximum limit on truck side $\mathrm{L} / \mathrm{V}$ ratio of 0.6 minimizes the risk of derailment due to rail rollover. A review of derailment criteria is presented in (Blader, 1989), which includes detailed discussions on single wheel, net axle, and truck side L/V ratios.
Table 2. Safety Criteria and Limits.

\begin{tabular}{|c|c|c|c|}
\hline Parameter & Safety Limit & $\begin{array}{l}\text { Filter/ } \\
\text { Window }\end{array}$ & Requirements \\
\hline \multicolumn{4}{|c|}{ Wheel/ Rail Forces } \\
\hline $\begin{array}{l}\text { Vertical } \\
\text { Wheel } \\
\text { Load Ratio }\end{array}$ & $\geq 0.1$ & $\begin{array}{l}5 \mathrm{ft} \\
\text { window }\end{array}$ & $\begin{array}{l}\text { No wheel of the equipment shall be } \\
\text { permitted to unload to less than } 10 \% \\
\text { of the static vertical wheel load. The } \\
\text { static vertical wheel load is the load } \\
\text { measured when wheel is stationary } \\
\text { on level track. }\end{array}$ \\
\hline $\begin{array}{l}\text { Single } \\
\text { Wheel } \\
\text { L/V Ratio }\end{array}$ & $\begin{array}{l}\leq \underline{\tan \delta-0.5} \\
1+0.5 \tan \delta \\
\text { (Nadal's } \\
\text { Limit) }\end{array}$ & $\begin{array}{l}5 \mathrm{ft} \\
\text { window }\end{array}$ & $\begin{array}{l}\text { The ratio of the lateral force that any } \\
\text { wheel exerts on rail to the vertical } \\
\text { force exerted by the same wheel } \\
\text { shall not exceed the safety limit } \\
\text { calculated for the wheel's flange } \\
\text { angle }(\delta) \text {. }\end{array}$ \\
\hline $\begin{array}{l}\text { Net Axle } \\
\text { L/V Ratio }\end{array}$ & $\leq 0.5$ & $\begin{array}{l}5 \mathrm{ft} \\
\text { window }\end{array}$ & $\begin{array}{l}\text { The net lateral force exerted by any } \\
\text { axle on the track shall not exceed } \\
50 \% \text { of the static vertical load that } \\
\text { the axle exerts on the track. }\end{array}$ \\
\hline $\begin{array}{l}\text { Truck Side } \\
\text { L/V Ratio }\end{array}$ & $\leq 0.6$ & $\begin{array}{l}5 \mathrm{ft} \\
\text { window }\end{array}$ & $\begin{array}{l}\text { The ratio of the lateral forces that the } \\
\text { wheels on one side of any truck exert } \\
\text { on an individual rail to the vertical } \\
\text { forces exerted by the same wheels on } \\
\text { that rail shall not exceed } 0.60 \text {. }\end{array}$ \\
\hline \multicolumn{4}{|c|}{ Accelerations } \\
\hline $\begin{array}{l}\text { Carbody } \\
\text { Lateral }\end{array}$ & $\begin{array}{l}0.5 \mathrm{~g} \\
\text { peak-to-peak }\end{array}$ & $\begin{array}{l}10 \mathrm{~Hz} \\
1 \mathrm{sec} \\
\text { window }\end{array}$ & $\begin{array}{l}\text { Measured as the algebraic difference } \\
\text { between the two extreme values of } \\
\text { measured acceleration in a one- } \\
\text { second time period. }\end{array}$ \\
\hline $\begin{array}{l}\text { Carbody } \\
\text { Vertical }\end{array}$ & $\begin{array}{l}0.6 \mathrm{~g} \\
\text { peak-to-peak }\end{array}$ & $\begin{array}{l}10 \mathrm{~Hz} \\
1 \mathrm{sec} \\
\text { window }\end{array}$ & $\begin{array}{l}\text { Measured as the algebraic difference } \\
\text { between the two extreme values of } \\
\text { measured acceleration in a one- } \\
\text { second time period. }\end{array}$ \\
\hline $\begin{array}{l}\text { Truck } \\
\text { Lateral }\end{array}$ & $\begin{array}{l}0.4 \mathrm{~g} \\
\text { RMS }\end{array}$ & $\begin{array}{c}10 \mathrm{~Hz} \\
2 \mathrm{sec} \\
\text { window }\end{array}$ & $\begin{array}{l}\text { Truck hunting shall not develop } \\
\text { below the maximum authorized } \\
\text { speed. }\end{array}$ \\
\hline
\end{tabular}

The last three safety limits apply to the vertical and lateral carbody accelerations and the lateral truck acceleration. Accelerations above the designated carbody limits are indicative of excessive and potentially unsafe carbody motions and may present unsafe conditions to vehicle occupants. (It should be noted that for vehicle qualification testing, tighter limits for carbody accelerations were recommended, namely $0.30 \mathrm{~g}$ peakto-peak for carbody lateral and $0.50 \mathrm{~g}$ peak-to-peak for carbody vertical, as dictated by good passenger ride quality practices.) Accelerations above the lateral truck limit are indicative of possible truck hunting. Truck hunting is undesirable, not only for ride quality but also for safety since it can potentially lead to wheel climb or other types of derailments.

\section{COMPARISONS OF PROPOSED STANDARDS WITH SELECTED ANALYSIS PREDICTIONS}

The response of a range of equipment was evaluated over a range of track geometry variations in order to determine the safe amplitudes of the track geometry variations. In selected cases, the analyses results were compared with test data, including those data measured during testing of the X-2000 and the ICE 
high speed trains on the Northeast Corridor (Whitten, B.T., Scales, B.T., 1993, and Whitten, B.T., Stout, D.R., 1994)

The equipment considered in these analyses include the AEM7 locomotive, the Amfleet coach car, and a design believed to be representative of Amtrak's high speed trainset -- the ATS locomotive. The dimensions and suspension geometry of the ATS locomotive used in the analyses are those of the power car of the French high speed train, the Train à Grande Vitesse (TGV) Atlantique. The suspension stiffness and damping parameters are a combination of estimated values and known values for the TGV Atlantique power car.

The track conditions evaluated included isolated and repeated alignment variations, and isolated and repeated track surface variations. The influence of speed on vehicle response to track geometry variations was determined for a wide range of conditions. The influences of equipment suspension parameters, such as secondary suspension damping, were also determined.

The analyses results indicate that equipment suspension parameters and configuration strongly influence vehicle response to track geometry variations. In particular, mounting of the traction motors and primary suspension design strongly influence vehicle response to track geometry, especially at speeds greater than $125 \mathrm{mph}$.

To illustrate the kind of vehicle/track interaction analyses that were performed in developing the high speed track geometry recommended specifications, the analyses of ATS locomotive response to a single track alignment variation at $160 \mathrm{mph}$ and ATS locomotive response to repeated track profile variations are described. The NUCARS simulation program (Klauser, P., Wilson, N., Handal, S., Dembosky, M., 1995) was used for the analyses of equipment response to track alignment variations. A linear lumped-mass model was developed and applied for analyzing equipment response to a range of track profile variations. The NUCARS and the A'GEM simulation program (Anderson, R.J. and Fortin, C., 1990) were used for analysis of vehicle response to selected track profile variations. To form more fully the technical basis for the recommended track geometry specifications, substantially more analyses were performed than are described.

\section{Alignment}

Figure 1. Shows an isolated track alignment variation considered in the effort. This variation is sinusoidal in shape, and is characterized by its wavelength and amplitude.

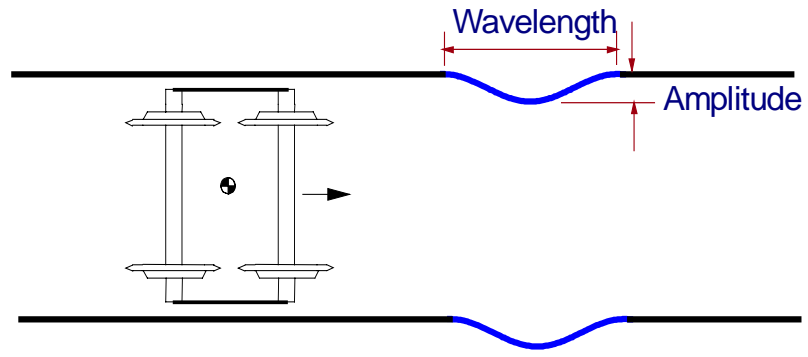

Figure 1. Single Perturbation Alignment Geometry.
Figure 2. Is a plot of the amplitude required to cause unsafe response of the ATS locomotive at $160 \mathrm{mph}$ and of the maximum amplitude permitted by the recommended alignment specification for Class 8 track as functions of track alignment variation wavelength.

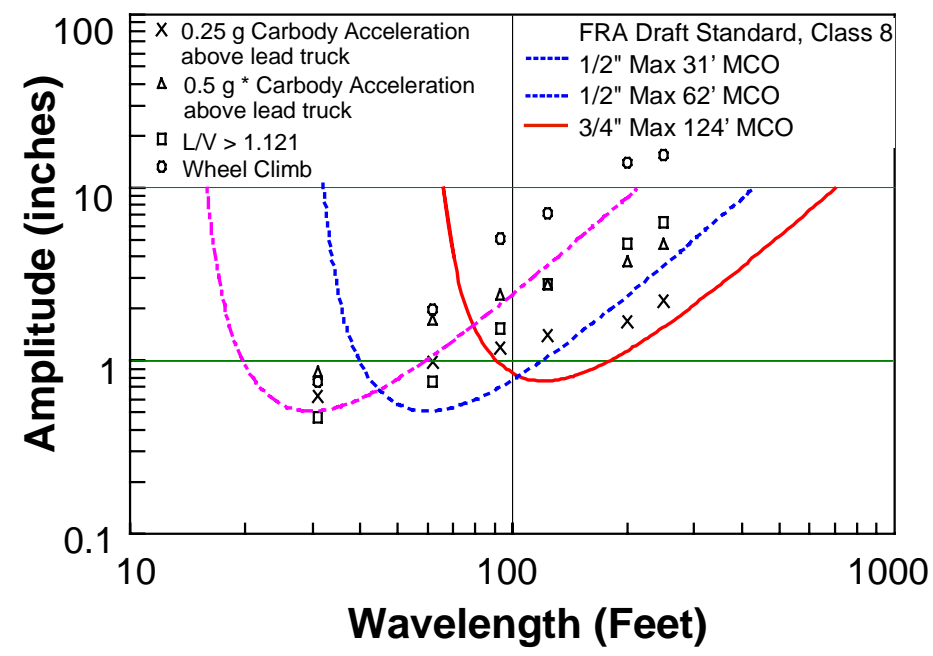

Figure 2. Single Alignment Perturbation Amplitude Required to Cause Unsafe Response, ATS Locomotive at $160 \mathrm{mph}$.

At short wavelengths -less than about 100 feet-- the maximum safe amplitude is limited by the wheel L/V ratio. This is owing to the wheel rapidly contacting the rail. The carbody motions at such wavelengths and amplitudes are not sufficient to cause excessive carbody accelerations. For the ATS locomotive traversing a track with a single alignment variation with a wavelength of 62 feet and $3 / 4$ inch amplitude, the lateral displacement of the lead wheelset and the carbody over the lead truck as a function of distance are shown in Figure 3 . As indicated in the figure, the suspension of the locomotive is effective in isolating the carbody from the track alignment variation.

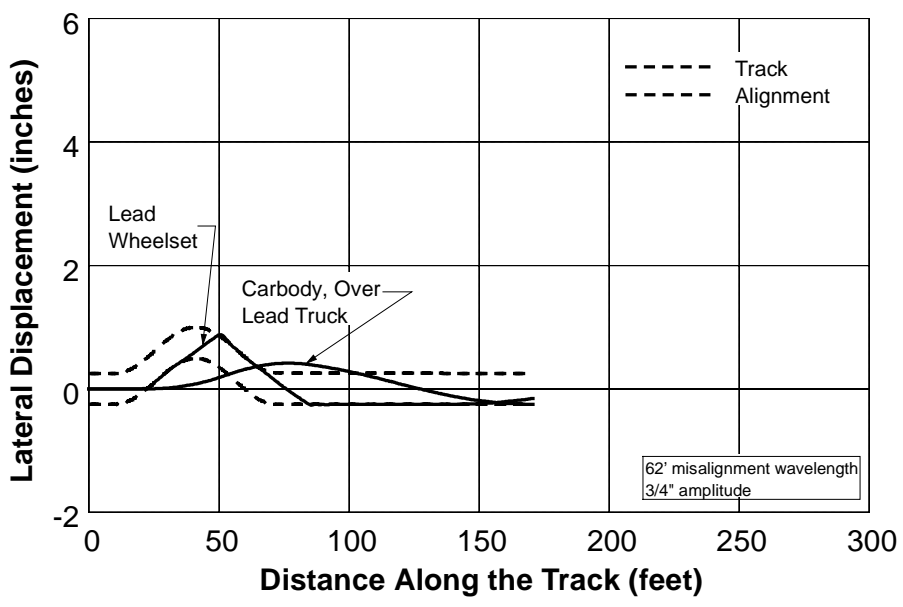

Figure 3. Carbody and Wheelset Lateral Displacement vs. Distance Traveled, Short Wavelength Alignment Variation, ATS Power Car at $160 \mathrm{mph}$. 
At long wavelength - those greater than 100 feet-the safe amplitude of alignment variations are limited by carbody accelerations. Figure 4 shows a plot of carbody and lead wheelset lateral displacement as a function of distance for the ATS locomotive traversing a track alignment variation with a 250 foot wavelength and $43 / 4$ inch amplitude. As shown in the figure, the amplitude of the carbody motions is slightly greater than the amplitude of the track alignment variation. At long wavelengths the carbody essentially follows the track. Track forces are well within safe limits for such alignment variations.

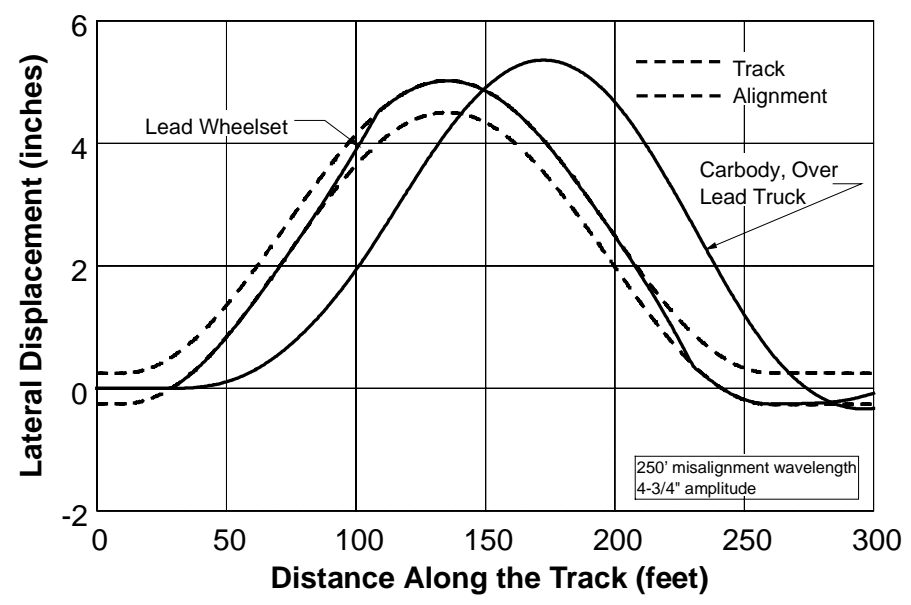

Figure 4. Carbody and Wheelset Lateral Displacement vs. Distance Traveled, Long Wavelength Alignment Variation, ATS Power Car at 160 mph.

The results for the response of other equipment analyzed over single alignment variations, and for all the equipment analyzed over repeated alignment variations showed similar trends as for the ATS locomotive response to a single alignment variation.

\section{Surface}

Equipment response to track profile variations was analyzed with the linear lumped mass model depicted schematically in Figure 5. This model has four degrees of freedom: carbody pitch and bounce, and vertical displacements of the front and rear trucks. The vertical displacement input to the primary suspensions of the trucks is the average of the vertical displacements of the wheelsets of the truck.

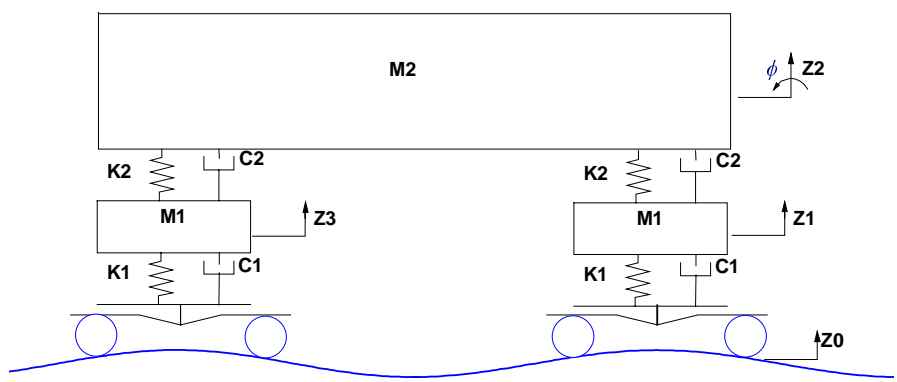

Figure 5. Bounce/Pitch Model.
Table 3. lists the truck and carbody bounce and carbody pitch natural frequencies and damping ratios for the ATS locomotive.

Table 3. ATS Locomotive Bounce/Pitch Natural Frequencies and Damping Ratios.

\begin{tabular}{||l|c|c||}
\hline \multicolumn{1}{|c|}{ Mode } & $\begin{array}{c}\text { Natural } \\
\text { Frequency }\end{array}$ & $\begin{array}{c}\text { Damping } \\
\text { Ratio }\end{array}$ \\
\hline \hline Body Bounce & $1.2 \mathrm{~Hz}$ & $24 \%$ \\
\hline Body Pitch & $1.3 \mathrm{~Hz}$ & $26 \%$ \\
\hline Truck Bounce & $8.1 \mathrm{~Hz}$ & $88 \%$ \\
\hline
\end{tabular}

Figure 6. Shows the amplitude of repeated profile variations required to cause excessive vertical accelerations in the operator's cab of the ATS locomotive at $160 \mathrm{mph}$. The figure also shows the maximum amplitude permitted for repeated track profile variations by the recommended track geometry specification for Class 8 track. The local minimum amplitude near the 30 foot wavelength is associated with the primary suspension natural frequency, while the local minimum amplitude near the 200 foot wavelength is associated with the body bounce natural frequency.

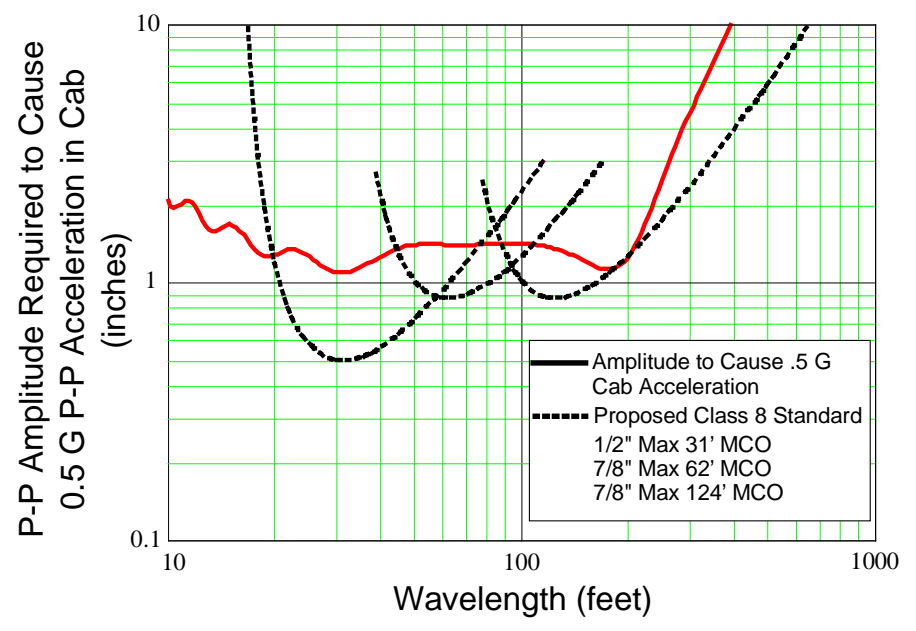

Figure 6. Track Surface Variation Amplitude Required to Cause 0.5 g Peak to Peak Carbody Acceleration vs Surface Variation Wavelength, ATS Power Car at 160 mph.

The analysis results for the response of other equipment over repeated track profile variations is similar for wavelengths greater than 100 feet; however, for wavelengths less than 100 feet there were significant differences in equipment response. Increased primary suspension natural frequency resulted in greater sensitivity to short wavelength profile variations at speeds greater than $125 \mathrm{mph}$. The analysis results for equipment response to single profile variations show that greater amplitudes can be permitted for single profile variations than can be permitted for repeated variations. 


\section{EVALUATION OF MEASURED TRACK GEOMETRY USING PROPOSED STANDARDS}

The highest speed passenger trains presently operating in the U.S. travel at $125 \mathrm{mph}$ on Northeast Corridor (NEC) track between Washington, DC and New York, NY. For train speeds above $90 \mathrm{mph}$, this track is maintained to the existing Class 6 standards or better, and is the most likely to be upgraded to support train speeds approaching $160 \mathrm{mph}$.

To assess the impact of upgrading to meet the proposed high speed track geometry specifications, track geometry measured over 114 miles of current NEC track between Philadelphia, PA and Washington, DC was examined. Table 4 presents a summary of the results of this examination.

Table 4. Summary of Results, Application of Proposed Standards to Measured NEC Track Geometry.

\begin{tabular}{|c|c|c|c|c|c|}
\hline \multirow[t]{2}{*}{ Type } & \multicolumn{2}{|c|}{$\begin{array}{l}\text { Current NEC } \\
\text { Track Limits } \\
\end{array}$} & \multicolumn{3}{|c|}{ Proposed Class 7} \\
\hline & Limit & $\begin{array}{l}\text { Excep } \\
\text {-tions }\end{array}$ & Limit & $\begin{array}{l}\text { Excep } \\
\text {-tions }\end{array}$ & $\begin{array}{l}\text { Single } \\
\text { Chord } \\
\text { Excep } \\
\text {-tions }\end{array}$ \\
\hline $\begin{array}{l}\text { Alignment } \\
31 \text { 'MCO }\end{array}$ & & & $0.50^{\prime \prime}$ & 13 & 4 \\
\hline 62'MCO & $0.50^{\prime \prime}$ & 14 & $0.50^{\prime \prime}$ & 21 & 12 \\
\hline 124'MCO & & & $1.25^{\prime \prime}$ & 1 & 0 \\
\hline $\begin{array}{l}\text { Profile } \\
31^{\prime} \mathrm{MCO}\end{array}$ & & & $1.25^{\prime \prime}$ & 0 & 0 \\
\hline 62'MCO & $0.50^{\prime \prime}$ & 24 & $1.25^{\prime \prime}$ & 0 & 0 \\
\hline 124'MCO & & & $1.50^{\prime \prime}$ & 3 & 3 \\
\hline $\begin{array}{l}\text { Gage } \\
\text { minimum }\end{array}$ & $56.0^{\prime \prime}$ & 4 & $56.0^{\prime \prime}$ & 4 & \\
\hline maximum & $57.25 "$ & 0 & $57.25 "$ & 0 & \\
\hline TOTALS & & 42 & & 32 & \\
\hline
\end{tabular}

Exceptions to the current NEC limits for track gage, alignment, and profile average about 1 exception in every 3 miles of track. Application of the proposed geometry limits for Class 7 track, which would permit vehicle speeds to $125 \mathrm{mph}$, revealed about 1 exception to these limits every 3.5 miles of track. Not only were fewer exceptions detected, a redistribution of the types of exceptions also occurred for the Class 7 case; this is consistent with the intent of the new standards to better identify and characterize the types and magnitudes of alignment and profile disturbances most likely to induce harsh vehicle response at these speeds. More alignment limits were reached, and 4 alignment disturbances were uniquely identified by the short wavelength 31-foot MCO limit. Although the alignment limit of 0.5 inches for the 62 ' $\mathrm{MCO}$ is the same for both the NEC limit and the proposed Class 7, the proposed Class 7 standard is based on the deviation of the MCO from uniformity; the definition of uniformity contributed to the identification of seven additional alignment exceptions not detected with the current NEC track limits. However, only 3 profile exceptions were found using the proposed Class 7 standards and these were all of long wavelengths, detected using the 124 ' MCO.

The proposed high speed track geometry specification limits for profile and alignment were also applied to the $125 \mathrm{mph}$ zones of the NEC between Philadelphia and Washington to determine the possible impact of raising these track segments to the proposed class 8 standard. This area is comprised of 101 track miles. This analysis was conducted using track geometry data from the Amtrak's February 1996 geometry inspection. Statistical data was obtained on the total number of alignment and profile exceptions, the number of those exceptions that were located by more than one of the chords, and the characteristics of the exceptions. Exceptions that were shorter than two current scans (four feet) or exceeded the proposed limits by less than 0.1 inch were eliminated to allow better comparison to exceptions reported by the existing equipment. A total of 33 exceptions were identified. Three were 31-foot chord profile exceptions and the remaining 30 were alignment exceptions. Four of the alignment exceptions were identified by both the 31 and 62-foot chords. Eleven alignment exceptions were identified by only the 31 -foot chord. Nine alignment exceptions were identified by only the 62-foot chord, and six alignment exceptions were located by only the 124-foot chord. This analysis indicates that in terms of alignment and profile, current $125 \mathrm{mph}$ track could be brought up to the proposed Class 8 standards by eliminating approximately one exception every three miles. It also proved the value of the multiple chord approach in locating defects over a range of wavelengths. Table 5 summarizes the results of the examination of the $125 \mathrm{mph}$ track.

Table 5. Summary of Results, Application of Proposed Standards to Measured 125 mph NEC Track Geometry.

\begin{tabular}{|c|c|c|c|}
\hline \multirow[t]{2}{*}{ Type } & \multicolumn{3}{|c|}{ Proposed Class 8} \\
\hline & Limit & Exceptions & $\begin{array}{c}\text { Single } \\
\text { Chord } \\
\text { Exceptions } \\
\end{array}$ \\
\hline $\begin{array}{l}\text { Alignment } \\
\text { 31' MCO }\end{array}$ & $0.50 ”$ & 15 & 11 \\
\hline 62' MCO & $0.50 "$ & 13 & 9 \\
\hline 124' MCO & $0.75^{\prime \prime}$ & 6 & 6 \\
\hline $\begin{array}{l}\text { Profile } \\
31{ }^{\prime} \mathrm{MCO}\end{array}$ & $0.75^{\prime \prime}$ & 3 & 3 \\
\hline 62' MCO & $1.25 "$ & 0 & \\
\hline $124^{\prime} \mathrm{MCO}$ & $1.25 "$ & 0 & \\
\hline TOTALS & & 33 & 29 \\
\hline
\end{tabular}

Figure 7 shows how the deviation of a single profile exception, shown as a space curve, would be measured using the 31, 62, and 124-foot MCO's recommended by the proposed geometry standards. Moving a 31-foot chord along the profile space 
curve, the MCO reaches a magnitude of 1.2 inches at the disturbance, which does not exceed the proposed Class 7 limit of 1.25 inches. Using a 62 -foot chord, the MCO reaches a magnitude of 1.4 inches, which does exceed the allowable 1.25 inch limit. Using the 124-foot chord, the MCO measures 1.8 inches, well above the allowable 1.5 inch limit for this chord length. The application of the three chords to this disturbance detects the exception and characterizes the profile disturbance as long in wavelength, likely to excite carbody modes and induce unsafe conditions at vehicle speeds of $125 \mathrm{mph}$.
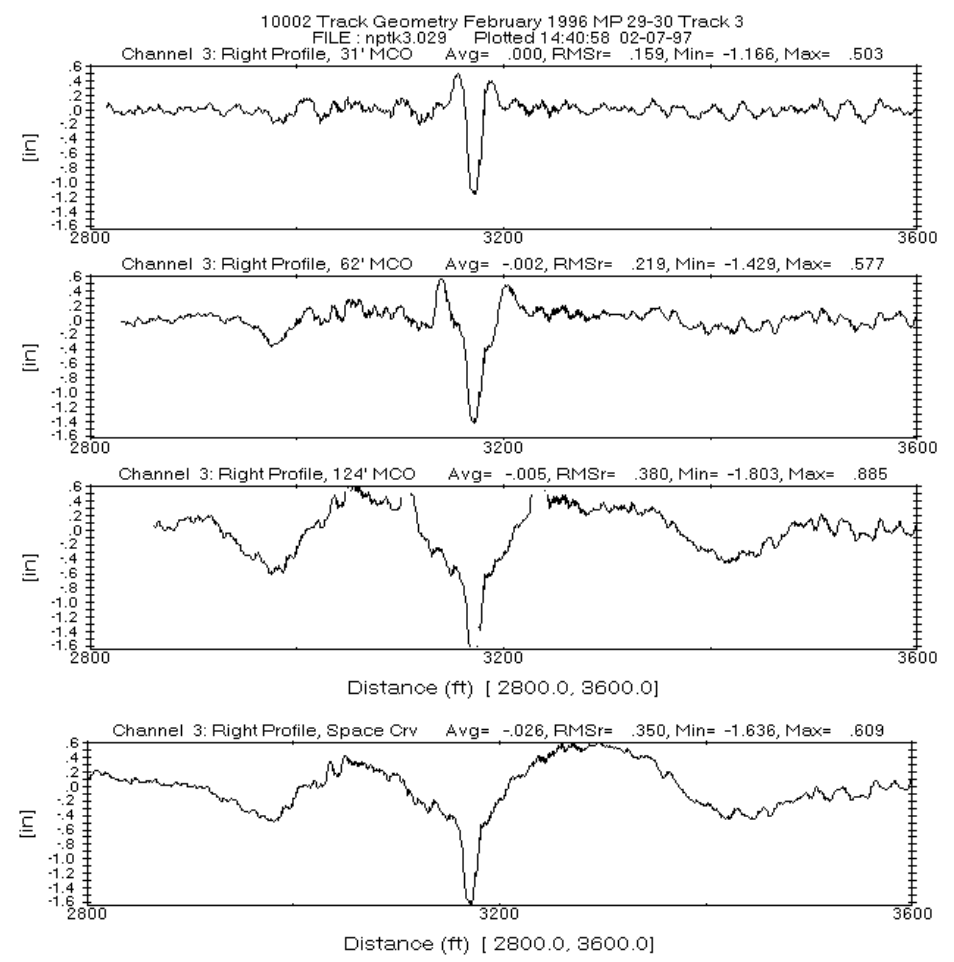

Figure 7. Measured Track Geometry , 31, 62, and 124 Foot MCO's, and Space Curve.

\section{COMPARISON OF PROPOSED HIGH SPEED TRACK GEOMETRY STANDARDS WITH FOREIGN PRACTICE}

The recommended track geometry specifications were compared with Société Nationale des Chemins de Fer Française (SNCF) track geometry safety limits for high-speed track. These limits apply for track on which the TGV operates at speeds up to $200 \mathrm{mph}$. Table 6 lists the SNCF safety limits. These limits apply to isolated and repeated geometry variations. If these limits are exceeded, then maximum train speed is limited to $144 \mathrm{mph}(230 \mathrm{kph})$ as long as the track geometry safety limits for $144 \mathrm{mph}$ operation are not exceeded. (While SNCF does not have track classes that are directly analogous to the FRA track classes, SNCF geometry safety limits are associated with speed ranges.) These safety limits are used in conjunction with maintenance limits.
Table 6. SNCF Track Geometry Safety Limits for High Speed Lines.

\begin{tabular}{|l|l|l||}
\hline \hline Parameter & Chord & Limit \\
\hline \hline \multirow{3}{*}{ Alignment } & $32.8^{\prime}(10 \mathrm{~m})$ & $0.47^{\prime \prime}(12 \mathrm{~mm})$ \\
\cline { 2 - 3 } & $101.7^{\prime}(31 \mathrm{~m})$ & $0.79^{\prime \prime}(20 \mathrm{~mm})$ \\
\hline \multirow{3}{*}{ Surface } & $40^{\prime}(12.2 \mathrm{~m})($ Mauzin $)$ & $0.59^{\prime \prime}(15 \mathrm{~mm})$ \\
\cline { 2 - 3 } & $101.7^{\prime}(31 \mathrm{~m})$ & $0.94^{\prime \prime}(24 \mathrm{~mm})$ \\
\hline Twist & $32.8^{\prime}(10 \mathrm{~m})$ base & $0.71^{\prime \prime}(18 \mathrm{~mm})$ \\
\hline \multirow{3}{*}{ Gage } & minimum & $56.2^{\prime \prime}(1427.5 \mathrm{~mm})$ \\
\cline { 2 - 3 } & mean $(100 \mathrm{~m}$ window) & $56.3^{\prime \prime}(1430 \mathrm{~mm})$ \\
\cline { 2 - 3 } & maximum & $57.6^{\prime \prime}(1454 \mathrm{~mm})$ \\
\hline Elevation & maximum & $7.08^{\prime \prime}(180 \mathrm{~mm})$ \\
\hline \hline
\end{tabular}

Figure 8 shows a comparison of the SNCF alignment geometry safety limits and the recommended Class 9 alignment geometry safety limits for a single alignment perturbation. For alignment geometry, SNCF practice uses two chords, while the recommended standard uses three. In the figure, the recommended alignment limits appear more restrictive than the comparable SNCF limits for alignment wavelength variations in the range of 50 to 100 feet; however, SNCF maintenance of way equipment uses a 65' 4" chord (20m). Application of the SNCF limits with the intermediate chord length results in smaller amplitudes being permitted for the 50 to 100 foot wavelength range than would be interpreted from SNCF track geometry safety limits.

The recommended specification for minimum gage for Class 9 is nearly identical to the comparable SNCF safety limit, while the recommended limit for maximum gage is more restrictive (57.25 inches vs 57.6 inches). There is no comparable recommended limit for the SNCF average gage in a 326 foot (100 m) moving window.

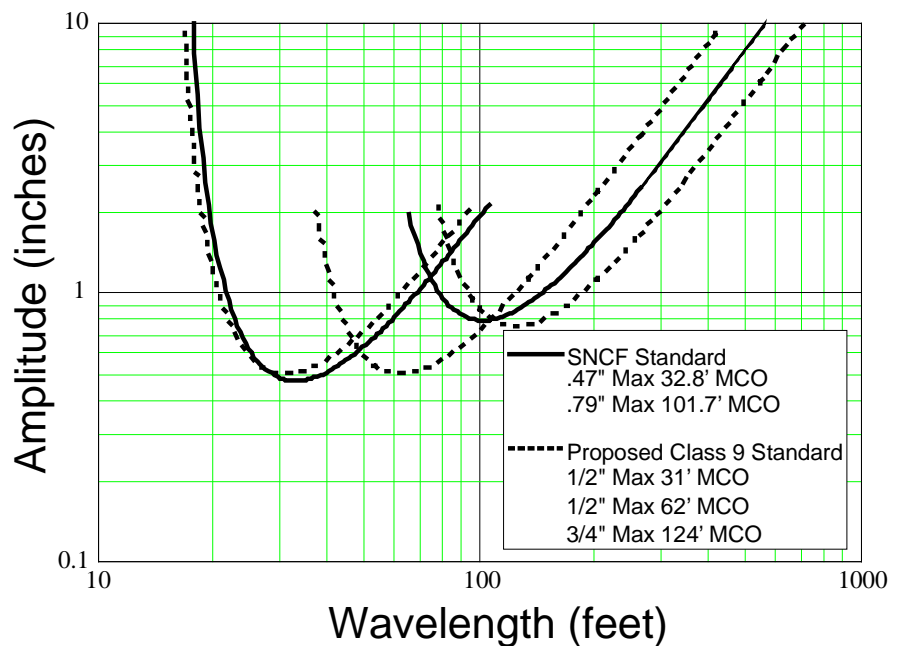

Figure 8. Comparison of SNCF Practice and Proposed Specification for Single Track Alignment Geometry Variation for $200 \mathrm{mph}$ Operation. 
Figure 9 shows a comparison of the SNCF surface geometry safety limits and the recommended Class 9 surface geometry safety limits for a single track surface perturbation. Multiple offsets are measured and mechanically combined for the 40 foot $(12.2 \mathrm{~m})$ chord measurement, according to the Mauzin car measurement system (Janin, G., 1983.) This technique extends the wavelength range of the measurement system beyond that of a mid-chord offset. The comparison in Figure 9 shows that the proposed specification is comparable to, but slightly less restrictive than, the SNCF safety limits for track surface geometry.

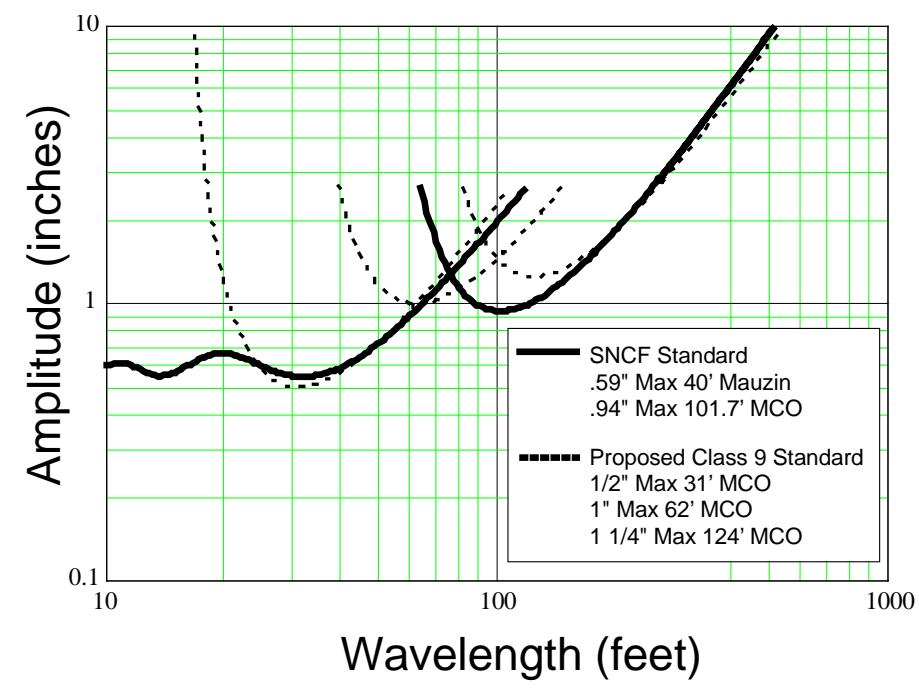

Figure 9. Comparison of SNCF Practice and Proposed Specification for Single Track Surface Geometry Variation for 200 mph Operation.

The recommended twist specification allows $1 \frac{1}{2}$ inches change in crosslevel in 62 feet, while SNCF safety limits allow 0.7 inches in 32.8 feet, which can be interpreted as allowing $1 \frac{3}{8}$ inches difference in crosslevel in 62 feet. The recommended specification is marginally less restrictive than SNCF practice for track twist.

The recommended specification for maximum superelevation is 7 inches, while the SNCF limit is 7.1 inches. The recommended limit is essentially identical with the comparable SNCF safety limit.

\section{CONCLUSION}

The recommendations resulting from the research efforts described in this paper were used with additional sources of information by the High Speed Task Group and the Track Working Group in developing track safety standards. Regulatory language was drafted to address track geometry and other safety issues, including employee qualifications, track classes, track structure and automated and visual track inspection. In November, RSAC submitted to Federal Railroad Administrator Jolene M. Molitoris a draft Notice of Proposed Rulemaking for proposed revisions to the track safety standards. The draft is currently under consideration within the Department of Transportation.

\section{ACKNOWLEDGEMENTS}

The authors would like to thank Mr. John Cunningham, Assistant Chief Engineer, National Railroad Passenger Corporation (Amtrak), Chair of the High Speed Task Group for his leadership and technical insight. Additional people who helped develop the technical information on high speed track geometry used by the High Speed Task Group include Dr. Herbert Weinstock, Michael Coltman, Brian Marquis, and Harvey Lee of the US Department of Transportation's Volpe Center, William O'Sullivan of the FRA Office of Safety, Michael Trosino and Conrad Ruppert from Amtrak, Jens Jacobsen and Henry Wise from the Brotherhood of Maintenance of Way Employees, George Young from American Association of State Highway and Transportation Officials, Gerard Cervi from SYSTRA, Dr. André Huber from GEC Alsthom, Ken Lawson from Rail Systems Research Associates, and Al Fazio from the High Speed Ground Transportation Association.

\section{REFERENCES}

Anderson, R.J. and Fortin, C., 1990, The A'GEM Rail Vehicle Dynamics Software Package User's Manual, Dynamics Laboratory Report, No. DL/RJA/90/1, Dept. of Mech. Eng., Queen's Univ., Kingston, Ont. Canada.

Blader, F.B., 1989, A Review of Literature and Methodologies in the Study of Derailments Caused by Excessive Forces at the Wheel/Rail Interface, Report No. R-717, Association of American Railroads.

Janin, G., 1983, Maintaining Track Geometry: Decisionmaking for Levelling and Lining, the 'Mauzin' Synthesis Method, Vol. 1, No. 1., French Railway Review.

Klauser, P., Wilson, N., Handal, S., Dembosky, M., 1995, Users Manual for NUCARS Version 2.1, SD-043-(rev 9/95), Association of American Railroads.

Manual for Railway Engineering, 1996, The American Railway Engineering Association.

Nadal, M.J., 1896, "Theorie de la stabilité des Locomotives, part 2, Mouvement de Lacet," Annales des Mines, Vol. 10.

Takai, H., Yazawa, E., 1994, A Study of Estimate Method of Vehicle Vibrations by Track Irregularities, A3-2-(4), Railway Technical Research Institute, Uchida Laboratory 2-8-38, Hikari-cho, Kokubunji-shi, Tokyo 185, Japan.

Whitten, B.T., Stout, D.R., 1994, ICE/USA Demonstration Vehicle Dynamics Tests, Test Report, DOT/FRA/ORD-94/25, Federal Railroad Administration, US Department of Transportation.

Whitten, B.T., Scales, B.T., 1993, X2000 U.S. Demonstration Vehicle Dynamics Tests, Final Test Report, DOT/FRA/ORD-94/15, Federal Railroad Administration, US Department of Transportation. 